\title{
Characterization of Neuropathic Pain in Sickle Cell Disease
}

M Nalbandian ${ }^{1}$, H Kyotakoze ${ }^{1}$, H Kaminsky ${ }^{1}$, D Keleny ${ }^{1}$, P Baghdasaryan ${ }^{1}$, A McDonald ${ }^{1}$, T Erwes ${ }^{1}$, T Mylläri ${ }^{2}$, K Nalbandyan ${ }^{3}$, TO Jalonen ${ }^{1}$

\begin{abstract}
Objective: Sickle cell disease (SCD) is a multifaceted, chronic disease that severely affects the quality of life of patients globally. Recurrent episodes of pain are a hallmark of SCD; however, there are limited data on the characterization of the pain. This paper characterizes the types of pain experienced by persons living with SCD in Grenada, West Indies. More specifically, it assesses the presence of neuropathic pain in these individuals. This study hopes to increase awareness of the types of pain in SCD and contribute to the development of effective pain management guidelines.

Methods: A cross-sectional study was performed to assess the presence and characteristics of pain in patients with a confirmed diagnosis of SCD in Grenada. Participants were selected randomly from the registry provided by the Sickle Cell Association of Grenada. The painDETECT questionnaire was used to provide quantitative data and the McGill-Melzack Pain Questionnaire to provide qualitative data.

Results: The study examined 63 participants, 24 males and 39 females, with a mean age of 21.16 years. In the McGill-Melzack Pain Questionnaire, participants chose pain descriptors for all three types of pain: nociceptive, affectivelevaluative and neuropathic. An independent sample median test found neuropathic pain descriptors to be significantly different across age groups $(\mathrm{p}=0.046)$. There was no age dependency in nociceptive and affective/evaluative pain. The mean final score of all participants in the painDETECT survey was 19.27 (95\% CI: 17.25, 21.29), which is a score suggestive of a neuropathic pain component. There was also a positive correlation of $0.41(\mathrm{p}=0.01)$ between age and painDETECT final score. Furthermore, a positive correlation of $0.56(\mathrm{p}<0.001)$ existed between the number of neuropathic pain descriptors chosen and the painDETECT final score.

Conclusion: The presence of all three types of pain, as well as the presence of neuropathic pain with increasing age, indicates the need for a multimodal pain management plan that is individually targeted and varied throughout the life of a patient with SCD.
\end{abstract}

Keywords: Grenada, neuropathic pain, pain, prevalence, sickle cell disease

From: ${ }^{1}$ Department of Physiology and Neuroscience, School of Medicine, St George's University, University Centre, St George's, Grenada, West Indies, ${ }^{2}$ Department of Computers and Technology, School of Arts and Sciences, St George's University, University Centre, St George's, Grenada, West Indies and ${ }^{3}$ Western University of Health Sciences, Pomona, California, United States of America.
Correspondence: Ms M Nalbandian, Department of Physiology and Neuroscience, School of Medicine, St George's University, University Centre, St George's, Grenada, West Indies. Email: mnalband@sgu.edu

West Indian Med J 2017; 66 (4): 503

DOI: 10.7727/wimj.2017.164 


\title{
Caracterización del dolor neuropático en la enfermedad de células falciformes
}

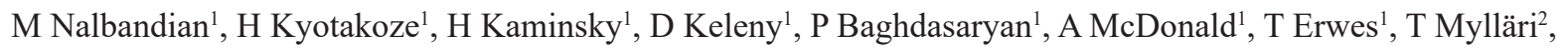
K Nalbandyan ${ }^{3}$, TO Jalonen ${ }^{1}$

\begin{abstract}
RESUMEN
Objetivo: La enfermedad de células falciformes (ECF) es una enfermedad multifacética, crónica, que afecta gravemente la calidad de vida de los pacientes a nivel mundial. Los episodios recurrentes de dolor son una característica distintiva de la ECF. Sin embargo, los datos existentes sobre la caracterización del dolor son limitados. El presente trabajo ofrece una caracterización de los tipos de dolor experimentado por las personas que viven con ECF en Granada, West Indies. Más concretamente, el trabajo evalúa la presencia de dolor neuropático en estos individuos. Este estudio persigue aumentar el conocimiento de los tipos de dolor en la ECF y contribuir al desarrollo de guias para el manejo efectivo del dolor.

Métodos: Se realizó un estudio transversal para evaluar la presencia y características del dolor en pacientes con diagnóstico confirmado de ECF en Granada. Los participantes fueron seleccionados aleatoriamente a partir del registro proporcionado por la Asociación de Sicklemia de Granada. El Cuestionario de Detección del Dolor fue utilizado para proporcionar los datos cuantitativos, y se usó el Cuestionario del Dolor McGill-Melzack para proporcionar los datos cualitativos.

Resultados: El estudio examinó 63 participantes (24 varones y 39 hembras) con una edad promedio de 21.16 años. En el Cuestionario de Dolor McGill-Melzack, los participantes eligieron descriptores de dolor para los tres tipos de dolor: nociceptivo, afectivo/evaluativo, y neuropático. Una prueba mediana de muestras independientes halló que los descriptores de dolor neuropático eran significativamente diferentes en todos los grupos de edad ( $\mathrm{p}=0.046)$. No hubo ninguna dependencia de la edad en el dolor nociceptivo y el afectivo/evaluativo. La puntuación media final de todos los participantes en el Cuestionario del Dolor fue 19.27 (IC de 95\%: 17.25, 21.29), lo cual es un resultado sugerente de un componente de dolor neuropático. También hubo una correlación positiva de $0.41(\mathrm{p}=0.01)$ entre la edad y la puntuación final del Cuestionario de Detección del Dolor. Además, se observó una correlación positiva de 0.56 $(\mathrm{p}<0.001)$ entre el número de descriptores de dolor neuropático escogidos y la puntuación final del Cuestionario de Detección del Dolor.

Conclusión: La presencia de los tres tipos de dolor, asi como la presencia de dolor neuropático con el aumento de la edad, indica la necesidad de un plan para el manejo multimodal del dolor, dirigido individualmente y variado a lo largo de la vida de un paciente con ECF.
\end{abstract}

Palabras clave: Granada, dolor neuropático, dolor, prevalencia, enfermedad de células falciformes

West Indian Med J 2017; 66 (4): 504

\section{INTRODUCTION}

Sickle cell disease (SCD) is a multifaceted, chronic, inherited disease that affects the quality of life of patients and their immediate families, and is also a costly public health concern. It is one of the most common haemoglobinopathies and is most prevalent in tropical regions, especially Africa, South America, the Caribbean, Asia and the Middle East, where a heterozygote advantage is offered by the disease against the Plasmodium parasite responsible for malaria. In equatorial parts of Africa, $20-40 \%$ of the population are heterozygous for the gene, a condition referred to as sickle cell trait, while 120 000-200 000 newborns are diagnosed with SCD each year (1).

In the United States of America (USA), the Centers for Disease Control and Prevention estimated that as 
of 2016, one in every 365 African-American newborns had SCD (2). In Grenada, home to the first identified patient with SCD, Walter Clement Noel (3), the true prevalence of SCD has not been reported as yet, though newborns and their mothers are currently screened for SCD. Recently, a cross-sectional study conducted at the General Hospital of Grenada (4) noted that between 2007 and 2013, there was a prevalence of approximately 1.49 per 1000 persons per year. This number was obtained from the number of hospital admissions compared to the general population, hence stressing that the actual prevalence would be higher since not all individuals with SCD presented to the hospital. Some Caribbean countries have released statistics related to SCD and sickle cell trait. In a Jamaican cohort study, approximately 100000 screenings were completed of non-operative deliveries, and about $10 \%$ of the newborns were found to have sickle cell trait (5). In a recent study conducted in Haiti during 2002-09, the prevalence of sickle haemoglobin was found to be $15.1 \%$ (6).

Patients with SCD characteristically experience episodes of vaso-occlusion, haemolysis and micro-infarcts, which cause varying degrees of pain throughout the body. In most cases, the disease is caused by a singlegene mutation of the beta-globin chain, whereby a negatively charged amino acid, glutamic acid, is replaced by a hydrophobic amino acid, valine. The resulting haemoglobin has a tendency to polymerize with other haemoglobin molecules during a state of stress or low oxygen, which creates sickled red blood cells. These cells have increased adhesion to the endothelium of the vasculature and decreased ability to manoeuvre through small vessels causing occlusion, which not only contributes to the experienced acute painful crises, but also cause complications such as acute chest syndrome, stroke, priapism, leg ulcerations and decreased kidney function. These sickled red blood cells also have a decreased lifespan which can cause anaemia (7).

Pain is a pervasive element of SCD that continues to be a major complaint of Grenadian patients, despite the efforts to build on current understanding of SCDassociated pain. In a study of patients with SCD in Grenada, $65 \%$ had visited more than one doctor for pain management within a period of one year, and $48 \%$ had visited the hospital at least three times due to pain. In the same study, the majority of Grenadian patients reported that pain resulting from SCD severely interfered with general activity, mood, ability to walk, work and sleep, relationships, and enjoyment of life (8).
This study explored and sought to quantify the amount of nociceptive pain (damage to body tissue; sharp, aching or throbbing pain), affective pain (unclear; perceptual-emotional reaction to the pain) and neuropathic pain (injury to central or peripheral nerves; tingling or burning) in patients with SCD. Characterizing the types of pain will contribute to awareness of the presence of pain in this condition and promote the development of adequate pain management guidelines for patients with SCD in Grenada, the Caribbean and globally.

\section{SUBJECTS AND METHODS}

A cross-sectional study was performed to assess the presence and characteristics of pain in patients with a confirmed diagnosis of SCD in Grenada. The study was approved by the St George's University Institutional Review Board (IRB \#14020). Participants were selected randomly from the registry provided by the Sickle Cell Association of Grenada (SCAG). Informed consent was obtained from volunteering participants and from parents of all individuals below the age of 18 years. The face-to-face interviews were conducted using the McGill-Melzack Pain Questionnaire and the painDETECT questionnaire. The painDETECT questionnaire is a useful screening measure for identifying neuropathic pain, which is represented by a score equal to or above 19 [score scale: 1-38] (9). The McGill-Melzack Pain Questionnaire assesses the intensity, quality and pattern of acute and chronic pain (10). The statistical analysis was conducted utilizing SPSS (Statistical Package for Social Sciences Version 23), a computer application that provides in-depth data access for analytical reporting. All interviewing researchers had completed the online training course of 'Protecting Human Research Participants' by the Office of Extramural Research of the National Institutes of Health.

\section{RESULTS}

This study consisted of interviews of 63 participants, 24 males and 39 females, with an overall mean age of 21.16 years. The first part of the interview involved questions from the painDETECT questionnaire, responses to which were quantified resulting in a final score. This specified if the pain was nociceptive (a final score of 0-12), unclear (a final score of 13-18) or neuropathic (a final score of 19-38). The average final score of all participants was 19.27 (95\% CI: 17.25, 21.29), which is a score suggestive of neuropathic components. There was a positive correlation, $0.41(p=0.01)$, between 
age and final score (Fig. 1), seen as an increase of the final score with age, and reaching a more stable level at around 15 years of age. Participants were further divided into three age groups, and the average final score of each of the groups was assessed. The average final score was 14.32 for participants under 10 years old $(n=19$; 95\% CI: 11.93, 16.70), 21.39 for participants of 10-20 years of age $(\mathrm{n}=18 ; 95 \%$ CI: $16.67,26.11)$ and 21.42 for participants of over 20 years of age $(n=26 ; 95 \%$ CI: $18.47,24.37)$. The average final score for the males was $17.88(\mathrm{n}=24,95 \%$ CI: $14.66,21.09)$ and the females was $20.13(\mathrm{n}=39 ; 95 \%$ CI: 17.46, 22.79).

A numerical pain scale provided in the painDETECT questionnaire was used to classify the intensity of the pain. Patients were asked to rate their level of pain on a scale of $0-10$, with 0 indicating no pain and 10 being the worst pain possible. Using this type of scale, 1-3 was indicative of mild pain, 4-6 moderate pain and 7-10 severe pain. The survey assessed the average level of pain at the time of the interview (2.24 \pm SD 3.13), the strongest pain felt in the past four weeks $(7.08 \pm \mathrm{SD}$ 3.43) and the average pain level in the past four weeks [5.30 \pm SD 3.01] (Figs. 2-4, respectively).

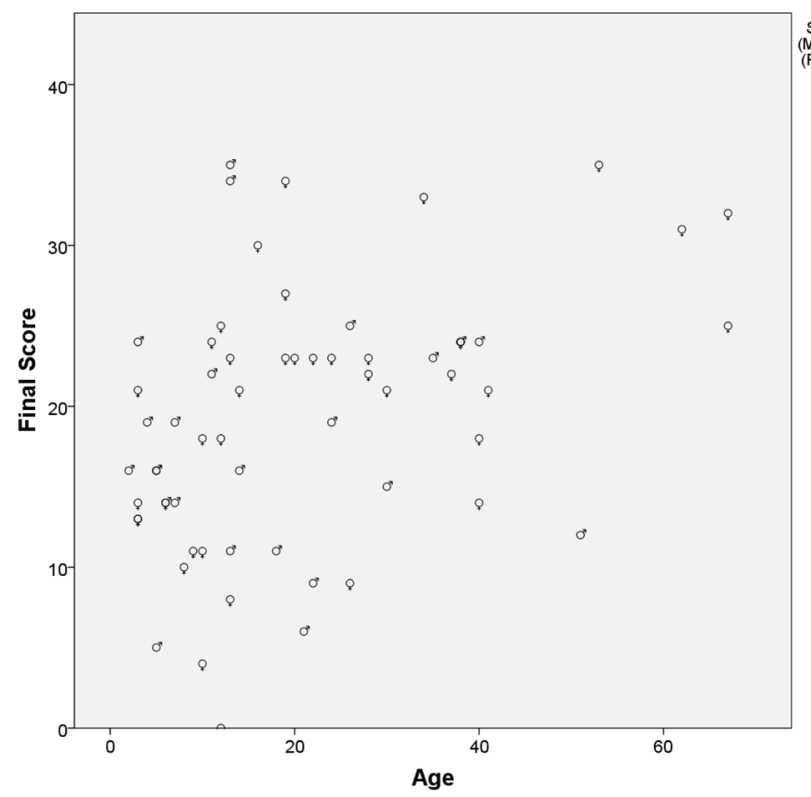

Fig. 1: The painDETECT survey provided a quantitative value for identifying if the pain exhibited by the participants was nociceptive (a final score of $0-12$ ), unclear (a final score of 13-18) or neuropathic (a final score of 19-38). There was a positive correlation, 0.41 ( $p=$ 0.01 ), between age and final score. The final score appeared to increase with age and stabilize around 15 years of age. The average final score for all participants was 19.27 (95\% CI: 17.25, 21.29). The average final score was 14.32 for participants under 10 years old (n $=19 ; 95 \%$ CI: 11.93, 16.70), 21.39 for participants aged $10-20$ years $(\mathrm{n}=18 ; 95 \%$ CI: $16.67,26.11)$ and 21.42 for participants over 20 years old $(n=26 ; 95 \%$ CI: $18.47,24.37)$.

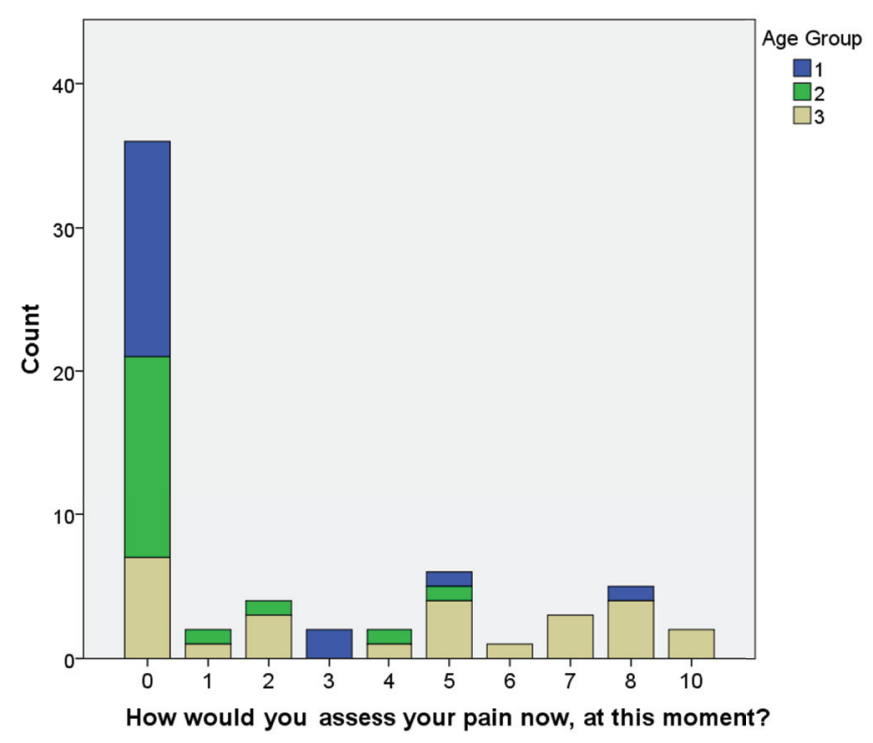

Fig. 2: How would you assess your pain now, at this moment? This bar graph shows the responses given when participants were asked for the level of pain at the time of the interview; the average response was 2.24 ( \pm SD 3.13). It also shows the proportion of responses from the three age groups: group 1 (blue) are participants under 10 years old $(n=19)$, group 2 (green) are participants aged $10-20$ years $(n=$ $18)$ and group 3 (brown) are participants over 20 years old $(n=26)$

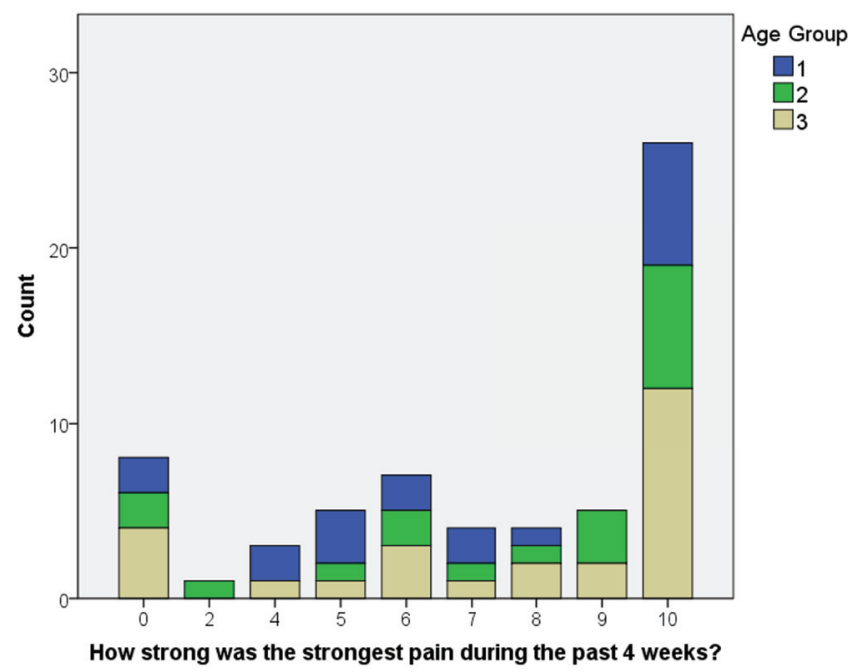

Fig. 3: How strong was the strongest pain during the past four weeks? This bar graph shows the responses given when participants were asked for the strongest pain experienced in the past four weeks; the average response was 7.08 ( \pm SD 3.43). It also shows the proportion of responses from the three age groups: group 1 (blue) are participants under 10 years old $(n=19)$, group 2 (green) are participants aged $10-20$ years $(\mathrm{n}=18)$ and group 3 (brown) are participants over 20 years old $(n=26)$.

An additional aspect of the painDETECT questionnaire assessed the pain behaviour pattern. Participants were asked to describe the course of pain as persistent pain with slight fluctuations, persistent pain with pain attacks, pain attacks without pain between them, and 


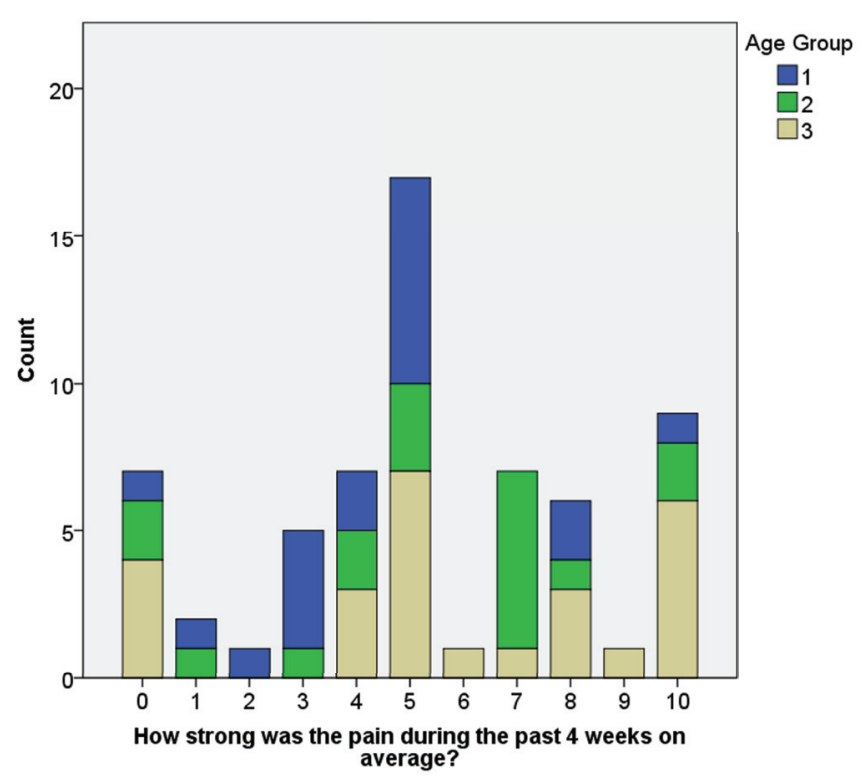

Fig. 4: How strong was the pain during the past four weeks on average? This bar graph shows the responses given when participants were asked for the average level of pain experienced in the past four weeks; the average response was 5.30 ( \pm SD 3.01). It also shows the proportion of responses from the three age groups: group 1 (blue) are participants under 10 years old $(n=19)$, group 2 (green) are participants aged $10-20$ years $(n=18)$ and group 3 (brown) are participants over 20 years old $(n=26)$.

pain attacks with pain between them (Fig. 5). A total of $66.7 \%$ of the participants chose the behaviour patterns associated with neuropathic pain, which is a description of pain attacks without pain between them and pain attacks with pain between them. The painDETECT questionnaire also showed that radiating pain, typical for neuropathic pain, was present in $81 \%$ of the participants.

The second part of the interview consisted of the McGill-Melzack Pain Questionnaire that investigated the characteristics of pain with a qualitative approach. In part 1 of this questionnaire, 'Where is your Pain', the participants were asked to locate parts of their body where they usually felt pain and discomfort. The participants experienced pain mostly in the abdomen (76\%), back $(63 \%)$, joints $(68 \%)$, head $(52 \%)$, and the extremities such as hands (49\%) and feet $(42 \%)$. In part 2 of the McGill-Melzack Pain Questionnaire, 'What Does Your Pain Feel Like?', the participants were presented with a group of 77 descriptor words that illustrated neuropathic, affective/evaluative or nociceptive pain. Neuropathic pain descriptors, along with affective/evaluative descriptors, were chosen $35 \%$ of the time, while nociceptive pain descriptors were chosen $31 \%$ of the time. The most common neuropathic pain descriptors chosen were aching (71\%) and spreading (68\%); nociceptive pain descriptors chosen were cramping (74\%) and hurting

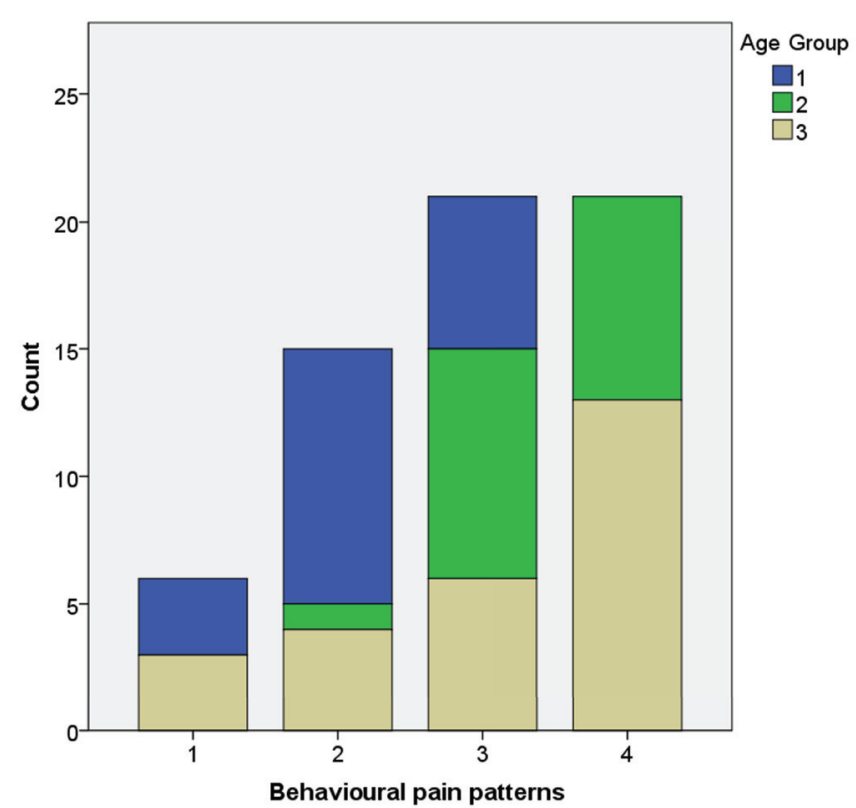

Fig. 5: Participants were asked to describe their pain patterns as one of four patterns: (1) persistent pain with slight fluctuations; (2) persistent pain with pain attacks; (3) pain attacks without pain between them; and (4) pain attacks with pain between them. Patterns 3 and 4 depict neuropathic pain, and $66.7 \%$ of the participants chose one of these two patterns. This bar graph further illustrates the proportion of responses from the three age groups: group 1 (blue) are participants under 10 years old $(n=19)$, group 2 (green) are participants aged $10-20$ years $(n=18)$ and group 3 (brown) are participants over 20 years old $(n=26)$. The majority of participants from groups 2 and 3 chose one of the neuropathic pain behavioural patterns.

(79\%); affective/evaluative pain descriptors chosen were tiring (51\%) and suffocating (62\%). When comparing the three age groups, an independent sample median test concluded that the neuropathic pain descriptors were significantly different across the three age groups $(p=0.046)$, but there were no significant differences across the age groups for the nociceptive and affective/ evaluative descriptors. Specifically, the youngest age group, under 10 years of age, chose fewer neuropathic pain words to describe their pain than the older age groups. There was also a positive correlation between neuropathic pain descriptors and the painDETECT final score of 0.56 [ $p<0.001]$ (Fig. 6). These data indicated that participants who were noted to exhibit neuropathic pain in the painDETECT questionnaire were more likely to choose the neuropathic pain descriptors to describe their pain.

\section{DISCUSSION}

Pain is one of the major complaints in patients with SCD throughout the world, and in some cultures, the disease is considered synonymous with pain (11). However, in Grenada, there are no guidelines for pain management in 


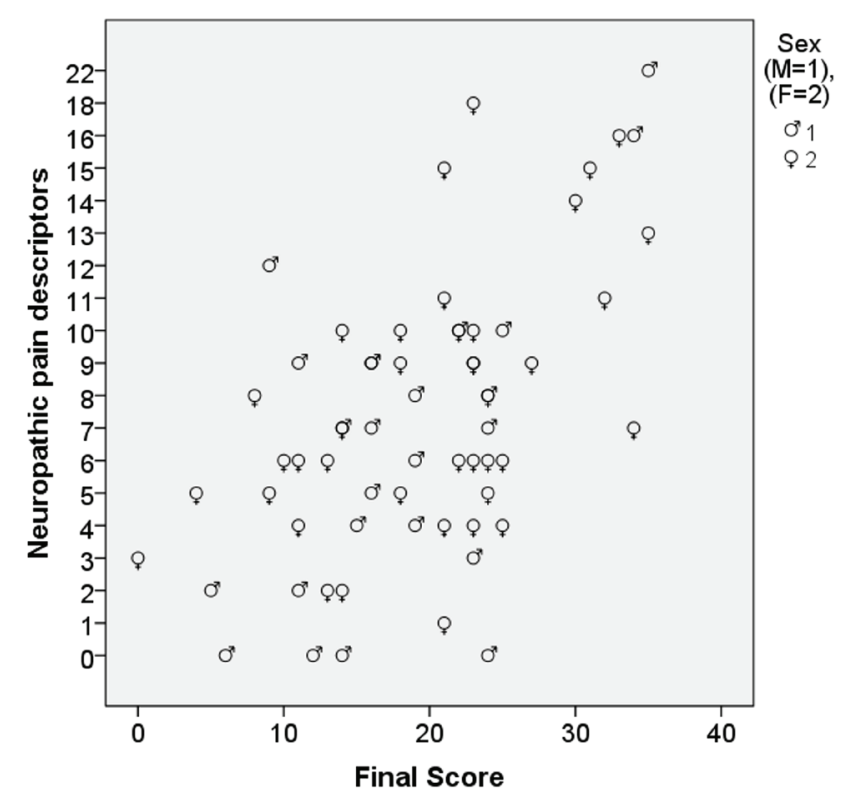

Fig. 6: The painDETECT survey provided a quantitative value for identifying if the pain exhibited by the participants was nociceptive (a final score of 0-12), unclear (a final score of 13-18) or neuropathic (a final score of 19-38). The McGill-Melzack Pain Questionnaire provided a qualitative approach for assessing the types of pain exhibited by these participants, specifically neuropathic, nociceptive and affective/evaluative, by utilizing pain descriptors. The participants with a higher final score in the painDETECT survey were more likely to pick neuropathic pain words to describe their pain; this relationship shows a positive correlation of $0.56(p<0.001)$.

SCD. Untreated pain has been shown to lower quality of life and cause recurrent absences from school and work. Ultimately, the symptoms of the condition and its effects on the individual's life contribute to the development of depression and increased morbidity $(8,11)$. Therefore, it is in the best interests of both the patient and healthcare professional to manage sickle cell pain effectively. The SCD pain is poorly understood because the various components of pain are not fully characterized, and therefore, the medication is not properly targeted.

Neuropathic pain is a form of chronic pain and may take years to develop. This is supported by our results of the correlation between the scores indicative of neuropathic pain in the painDETECT questionnaire and increased age (Fig. 1). Furthermore, although the pain descriptors chosen by each patient in the McGillMelzack Pain Questionnaire were spread among all three types of pain, neuropathic pain descriptors were found to be less common in the younger age groups. However, it should be noted that children have difficulties in describing their symptoms and the parents at times assist in answering them. After the age of 10 years, most of the participants had a final score indicative of neuropathic pain. The relationship between the
painDETECT final score and neuropathic pain descriptors asserted the reliability and coherence between the two surveys: participants with a higher final painDETECT score (indicative of neuropathic pain) were more likely to pick neuropathic pain descriptors than participants with a lower final score. The small number of participants above the age of 40 years in the study could reflect the lower life expectancy of persons with SCD. The average life expectancy of patients with SCD in the USA is 42 years in men and 48 years in women, and even lower in developing countries (12).

The painDETECT questionnaire also provided a numerical pain scale for listing the intensity of pain. At the time of the interviews, the mean score for the intensity of pain was only 2.24 , indicating that the participants in general did not suffer from severe pain at the time of the survey. However, the mean score of 5.30 for the average level of pain strongly indicated that these individuals lived with a moderate level of constant pain which was not alleviated by their medication and care. This is in line with a 2014 study carried out in Grenada, which revealed that $41 \%$ of patients with SCD felt that the prescription medication they were receiving was ineffective (8). The selection of the various pain descriptors highlighted the importance of multimodal treatment regimens in treating all three types of pain adequately.

The individuals interviewed for their level of pain were members of SCAG which aims to support patients in overcoming the complications of SCD. The sample population may underestimate country-wide levels of pain as there are individuals who are living with SCD but are not registered with SCAG.

\section{CONCLUSION}

Sickle cell disease is a prevalent, painful condition, especially in tropical developing countries. The inherited nature of the disease as well as its chronic course with periods of life-threatening crisis highlight the importance of adequate treatment. When providing care, clinicians should consider that patients with SCD exhibit neuropathic, nociceptive and affective types of pain. This research suggests that guidelines need to be developed to treat and target the various types of pain adequately. Treatment protocols used in developed countries, such as the USA, could be considered as models, as prompt pain control and therapeutic treatments have been shown to increase lifespan and enhance the quality of life of patients suffering from SCD (13). All Caribbean collaborative efforts to increase screening, education and care related to SCD and sickle cell trait would be necessary 
to alleviate the severe burden of SCD on the health and economy of individuals and countries.

This study utilized two major screening tests to categorize the types of pain experienced by the patients with SCD in Grenada, in order to stress the importance of individually targeted and age-dependent pain management from birth to adulthood.

\section{ACKNOWLEDGEMENTS}

The authors thank Mrs Christine Braithwaite, Dr Mondel George, Nurse Lewisa Ratoo and other SCAG members for their participation and support throughout this project. Special thanks go to Dr Aleksandr Mylläri for statistical analysis, as well as to Elio Plevneshi and the rest of the St George's University School of Medicine NeuroResearch group students for participating in the SCD project in Grenada.

\section{REFERENCES}

1. Randolph TR, Wheelhouse J. Novel test method (sickle confirm) to differentiate sickle cell anemia from sickle cell trait for potential use in developing countries. Clin Lab Sci 2012; 25: 26-34.
2. Centers for Disease Control and Prevention. Sickle cell disease (SCD): data \& statistics. Cited June 2, 2016. Available from: www.cdc.gov/ ncbddd/sicklecell/data.html.

3. Herrick JB. Peculiar elongated and sickle-shaped red blood corpuscles in a case of severe anemia. Arch Intern Med 1910; 6: 517-21.

4. Nalbandian M, Kaminsky H, Baghdasaryan P, Keleny D, Nalbandyan K, Jalonen TO. Epidemiology of the sickle cell disease in Grenada: a comparison with Haiti, Jamaica and United States of America. West Indian Med J 2017; 66: 491-6.

5. Hanchard NA, Hambleton I, Harding RM, McKenzie CA. The frequency of the sickle allele in Jamaica has not declined over the last 22 years. Br J Haematol 2005; 130: 939-42.

6. Randolph TR. Estimated prevalence of sickle cell in northern Haiti. Clin Lab Sci 2010; 23: 79-83.

7. Manwani D, Frenette PS. Vaso-occlusion in sickle cell disease: pathophysiology and novel targeted therapies. Blood 2013; 122: 3892-8.

8. Shah PD, Macpherson CC, Akpinar-Elci M. Impacts of undertreated sickle cell pain in the Caribbean. West Indian Med J 2014; 1: 63-6.

9. Cappelleri JC, Koduru V, Bienen EJ, Sadosky A. A cross-sectional study examining the psychometric properties of the painDETECT measure in neuropathic pain. J Pain Res 2015; 8: 159-67.

10. Melzack R. The McGill pain questionnaire: major properties and scoring methods. Pain 1975; 1: 277-99.

11. Anie KA, Egunjobi FE, Akinyanju OO. Psychosocial impact of sickle cell disorder: perspectives from a Nigerian setting. Glob Health 2010; 6: 2 .

12. Hassell KL. Population estimates of sickle cell disease in the US. Am J Prev Med 2010; 38: S512-21.

13. Quinn CT, Rogers ZR, McCavit TL, Buchanan GR. Improved survival of children and adolescents with sickle cell disease. Blood 2010; 115: 3447-52. 